\title{
Socialization: \\ A Requisite for Writing the Doctoral Dissertation?
}

\author{
By Gail D. Caruth ${ }^{*}$
}

\begin{abstract}
Low completion rates for doctorates presents a problem for higher education in the United States. Successful completion is essential and maintaining a pool of doctorates guarantees a sufficient number of educators and researchers. The purpose of this paper was twofold: to determine the number of doctoral degrees awarded during the 2012-2013 academic year at public, private and for-profit universities in the United States and, also to share these findings with the academic community. This study is significant because identifying where doctoral degrees are awarded is important to higher education because colleges and universities need to know where the doctoral graduates are before administrators can begin working to eliminate the barriers to completion of the degree. This research study was an archival quantitative, data mining study using data from the Integrated Postsecondary Education Data System (IPEDS) of the National Center for Education Statistics (NCES). This study identified the number of doctoral degrees awarded. The findings from the review of the literature and the study suggested that approximately 175,865 doctoral degrees were not awarded during the 2012-2013 academic year in the United States potentially due to insufficient socialization during the dissertation process.
\end{abstract}

Keywords: dissertation, dissertation socialization, doctoral dissertations

\section{Introduction}

A problem exists in doctoral programs in the United States. Nearly half of the students who register in doctoral programs drop out prior to completing the degree (Burkard, 2014; Cakmak, Isci, Uslu, Oztekin, Danisman, \& Karadag, 2015; King \& Williams, 2014). Low completion rates of aspiring doctorates alert researchers in higher education to focus on reasons for dissertation delays with dissertation completion and length of time to completion. Administrators and professors aspiring to earn their doctorates never make it to institutions of higher education leadership when these students do not complete their terminal degrees. Consequently, these potential resources are forever lost to the academy. This loss is distressing to many institutions due to the reduction of available resources, not to mention the negative effects on the students themselves who did not complete their degrees. King and Williams (2014) maintained that doctoral degrees are essential for the future success of administrators and researchers.

According to the United States Department of Education's National Center for Education Statistics (NCES), the average cost of a doctorate degree at public institutions during 2009-2010 was $\$ 8,763$ per year while the cost at

* Adjunct Faculty, Texas A\&M University, USA. 
private institutions during the same year was $\$ 20,368$. Generally it takes five full-time years to complete a doctoral degree. Hence the cost of earning a doctorate was between $\$ 43,815$ and $\$ 101,840$ (U.S. Department of Education).

In a qualitative method descriptive, single-case design study (King \& Williams, 2014) on students under pressure to finalize their dissertation proposals, findings suggested that students became aware of a number of barriers to completing their degrees. Some of these barriers were peripheral to the program such as advising problems, learning inadequacies, and personal responsibilities. However, Kuo (2009) suggested that insufficient undergraduate preparation, reduced intrigue, inability, amount of study time, and comprehensive exam scores are possible barriers to completing doctoral dissertations. On the other hand, Burkard (2014) alleged that the lack of preparation, committee chair and candidate relationships, candidate and faculty expectations, candidate and faculty relationships, and candidate support systems were barriers for completing the dissertation in addition to finances, individual traits, and university and department policies.

King and Williams (2014) recommended that providing dissertation proposal development courses; making certain doctoral candidates have a good understanding of the content being researched, of the design of the research project, of the statistical analysis required, of how to write well, and of how to write critically; providing sufficient resources to students deficient in skills necessary to complete a dissertation; and being attentive to the socialization of doctoral candidates throughout their doctoral programs would minimize the effects of potential barriers to completing doctoral degrees. Also, Kuo (2009) recommended that doctoral candidates need to be able to describe their dissertation in a sentence. In addition, Burkard (2014) recommended ensuring opportunities for research assistantships and chances for working with faculty on research projects, positive committee chair and candidate relationships, mutual candidate and faculty expectations and relationships, and support from friends and peers were important for completion.

The need for doctorates creates a dissertation black market. "Dissertations for sale" (Osipian, 2012, p. 76) is a practice of "educational corruption" (p. 76) and refers to customized dissertations. These customized dissertations are written by ghost writers for wannabe doctors for a price rather than doctoral candidates conducting their own research and writing their own papers. Osipian alleged that there are a number incidents of reported doctorates awarded through the practice of dissertations for sale even though there is no empirical research available to support this allegation. Investigating the practice of dissertations for sale is important because the actual price of this practice goes beyond the sale of dissertations. The cost to higher education and society by the award of "fake doctorates" (p. 82) in order to help increase the number of doctoral graduates is extensive. There is the cost of the damage to the standing of an earned doctoral degree, for example, as well as the cost of the damage to the overall integrity of research and scholarship in higher education.

There is a problem in higher education if doctorates are entering doctoral 
programs but not graduating. The purpose of this paper was to determine the number of doctoral degrees awarded during the 2012-2013 academic year at public, private, and for-profit universities in the United States. This study is significant because identifying where doctoral degrees are awarded is important to higher education because colleges and universities need to know where the doctoral graduates are before administrators can begin working to eliminate the barriers to completion of the degree.

A review of the literature presents a compilation of research, peerreviewed journals, non-peer reviewed journals, books, and online sources on doctoral dissertations. The academic databases used were from the online library of Texas A\&M University-Commerce and included, but were not limited to, Academic Search Premier, EBSCO, Education Research Complete, Eric, ProQuest, and Sage Publications. The key descriptive terms used for this research were dissertations, doctoral dissertations, socialization, and dissertation socialization.

\section{Review of the Literature}

Successful completion rates for doctoral degrees are essential for any profession. Having a pool of doctorates guarantees a sufficient number of educators and researchers in any field of study. Research has suggested that there is attrition at four junctures during the doctoral program (within the first 2 years, between years 2 and 3, between years 3 and 5 and after 5 years or more of study). More specifically, attrition from doctoral programs occurs when candidates are at the dissertation stage. The last year of a doctoral program is generally the most demanding period for doctoral candidates inasmuch as the golden-ring of achievement is in sight. There is an enormous amount of work and enthusiasm necessary at this point. There are many tasks to complete, research articles to review, findings to analyze, and conclusions to be drawn during the writing of a dissertation. Also, there are institutional and departmental requirements to address, manuscripts to publish, classmates with whom to collaborate, and positions to apply for during the dissertation process (Marino, Stefan, \& Blackford, 2014).

Expectations for the doctoral dissertation differ from program to program. Some doctoral programs strive to turn out future researchers or academics in anticipation that the dissertations from their doctoral candidates will expand on a theoretical model that will also employ an advanced data-analysis technique. Others anticipate turning out scholar practitioners (Jacobs, 2013). Still other doctoral programs anticipate student rigor preparation facilitating doctoral degree completion (Burkard, 2014).

In addition to differences of expectations between programs are the differences between faculty, departments, institutions, etc. In a meta-analysis of educational research from the Universidade Nova de Lisboa in Portugal (Alves, Azevedo, \& Goncalves, 2012) for example, findings raised questions regarding the characteristics, research, and teachings of the educational 
scientific field within the University. Educational research is an undeveloped field which may account for some of the questions raised because faculty have a propensity to introduce methods from their own areas of interest and experience, as alleged by Alves et al.

As another example, some faculty are becoming increasingly active in community engagement, defined as those in higher education institutions collaborating together for mutual information exchange, in addition to the responsibilities of teaching, research, and service. Consequently, students are also becoming interested in research in community engagement. Jaeger, Sandmann, and Kim, (2011) questioned whether those guiding doctoral candidates were either discouraging or encouraging dissertation research in the area of community engagement.

An interpretive, qualitative study (Jaeger et al., 2011) was conducted on four doctoral students interested in doing community-engaged dissertation research to examine the relationship between doctoral candidates doing community-engaged dissertation studies and those in the role of facilitating the process, such as the chair. Research has repeatedly demonstrated that the chair-candidate relationship was notably tied to academic success (Jaeger et al., 2011; Neale-McFall, \& Ward, 2015). Moreover, findings indicated that problems with chair-candidate relationships were causes for candidates failing to attain the doctorate (Cakmak et al., 2015; Jaeger Sandmann, \& Kim, 2011).

\section{Relationships and the Dissertation Process}

Research into chair-candidate relationships suggested that gender, ethnicity, education, and other differences impact any research relationship. Particularly, research revealed that the chair-candidate relationship is a veiled and controlled relationship similar to the "master-slave relationship" (Wisker \& Robinson, 2014, p. 191) and possible "cultural imperialism" (p. 191). Wisker and Robinson alleged that a number of foreign students were even suppressed or sought remedial education from host universities and that this practice has gone so far as to lead to mistreatment of candidates.

Research is a long way from being evenhanded. Furthermore, control functions in the selection of who manages the research, how the research is conducted, what is examined, what the results are, whether the results bolster bias, and whether results are disregarded or used to make a difference. Hence, valuing subtle distinctions is recommended for anyone facilitating the doctoral dissertation process (Wisker \& Robinson, 2014).

Chairs also impact candidates' perceptions of research topics, as maintained by Jaeger et al. (2011). As a consequence, more focus needs to be given to chair-candidate relationships for doctoral candidates selecting a dissertation research topic to encourage chairs to be aware of and to learn from candidates and to deliberately demonstrate "mutuality and reciprocity" (p. 21). Jaeger et al. (2011) uncovered five common characteristics of chair-candidate relationships: a) education and qualifications count, b) chairs and candidates 
learn together, c) chair-candidate relationships can become synergistic, d) chairs frequently act as translators and advocates, and e) chairs and candidates both claimed that dissertation studies may need organizational backing.

Mhunpiew (2013) claimed that facilitating the dissertation process encompasses roles such as "coach, teacher, friend, colleague, trainer, good role model, and guide" (p.120) with the goal to "facilitate 'total' development for each student" (p.122). The chair is an essential resource for candidates during the dissertation process. The most effective chair "generally is one who shares the student's topic of interest; has served on dissertation committees several times before taking on the role of a chair; and is familiar with the process, its pace, nuances, and possible barriers" (Berger, 2015, pp. 172-173). Kuo (2009) alleged that candidates with effective chairs perceived better progress with satisfying degree obligations than do candidates with ineffective chairs.

Learning is enhanced when candidates are facilitated through the dissertation process with an informed chair and committee of professors who are capable of providing fundamental encouragement and guidance. This interaction of informed encouragement and guidance allows candidates to develop into specialists in the area of study during the dissertation process (Liechty, Liao, \& Schull, 2009).

Moreover, dissertation success is dependent on the candidates' current knowledge and the potential for development; the facilitation by others who are more knowledgeable to provide encouragement and guidance according to the needs of the candidate; and the ability of the program, department, and university to provide programs, workshops, and courses. The candidate, chair, program, department, and university are all indispensable for effective learning and dissertation completion (Liechty Liao, \& Schull, 2009). Alternatively, candidates, chairs, programs, departments, and universities are also negatively impacted when candidates fail to graduate (Neale-McFall \& Ward, 2015).

Candidates who select dissertation chairs based on their perceptions of how the chairs work and how the candidates will work with the chairs tend to have more positive experiences than candidates who select chairs based on prior personal relationships. Basing selections on chairs' work ethics, patience and endurance, interests in candidates, support for candidates, and pattern of providing valuable feedback to candidates can lead to more positive dissertation experiences (Neale-McFall \& Ward, 2015).

In a mixed-methods study on the positive and negative perceptions of dissertation experiences, Burkar (2014) recommended to those facilitating the dissertation process to establish a chair-candidate relationship that is designed to persevere through dissertation challenges. Establishing this relationship should include clarifying expectations and the process for handling differences in advance. Both the chair and candidate must be responsible for the quality of the relationship, as maintained by Burkar. Chairs may need to take the first step during a disagreement however, because they hold the power. Chairs and candidates should be well versed on the policies and procedures guiding the dissertation process. Burkar claimed that candidates that had previous experiences working on research projects with chairs reported more positive 
experiences with the dissertation process. Burkar also recommended that chairs should be provided training and mentoring opportunities to facilitate the dissertation process more effectively for the benefit of the candidates.

Burkar (2014) alleged that the committee-candidate relationship did not impede doctoral dissertation completion; in fact, the relationship often appeared to assist the process. Committee members that typically stay on the sidelines until they are needed for support and encouragement expedite completion time. In situations where there are conflicts with chairs and committee members candidates tend to experience more negative perceptions of the dissertation experience.

At the point when doctoral committee members are selected, not all candidates are aware of the roles and responsibilities of the committee members. Wu and Beaunae (2014) suggested that committee members should be experienced with the research method of the study. $\mathrm{Wu}$ and Beaunae also suggested that candidates should work together closely with their committee members to establish positive connections ensuring a positive experience throughout the dissertation process.

Chairs and committee members who encourage scholarship and publication during doctoral candidacy increase the likelihood of student engagement in scholarly activities. For example, published doctoral candidates are more apt to respond to journal editors' and reviewers' comments, present data, and succinctly clarify methodology and results then those who are not experienced in scholarship and publication. As a result, publishing during candidature encourages and cultivates fundamental academic habits. Some of these habits include replying to helpful comments, communicating efficiently, persisting, and believing in one's self, as maintained by Sharmini, SpronkenSmith, Golding, and Harland (2015) result in increased socialization.

Alternatively, suggesting to doctoral candidates to connect with reputable and published researchers and scholars in their fields has proven to be profitable and rewarding. All too often doctoral candidates are hesitant about contacting recognized scholars. However, Berger (2015) claimed that approaching scholars during the dissertation process has been worthwhile and that established scholars are frequently interested in providing guidance to aspiring scholars.

Knowledge sharing facilitates the effectiveness in completing the work effort and reaching one's objectives. Therefore, improved socialization between colleagues enhances knowledge sharing. The better the quality of relationships between key players the better the socialization. The better the socialization results in a greater degree of satisfaction in the experience (HungWen, 2011).

\section{Writing the Dissertation}

Writing the dissertation is a process that is high-risk for aspiring graduates and targeted interventions at this stage are warranted (Liechty Liao, \& Schull, 
2009); is a process that necessitates candidates to confront numerous educational, ritual, dictatorial, and schedule hardships (Wu \& Beaunae, 2014); and is a process that potentially delays the attainment of doctoral degrees (Kuo, 2009). Writing the doctoral dissertation represents the most demanding time of the academic career of candidates (Burkard, 2014; Kuo, 2009; Jacobs, 2013) and student attrition rates, in some measure, can be connected to the challenges in writing the dissertation (Burkard, 2014). For the majority of doctoral candidates however, writing the doctoral dissertation also represents the most rewarding time of their academic career.

Up to this point candidates have concentrated by and large on the academic activities of established scholars. Now candidates concentrate wholly on areas that are of particular interest to them while writing their dissertations (Jacobs, 2013). The process of conducting research can be troublesome for experienced researchers. The process of conducting research can be even more troublesome for inexperienced researchers. The policies and conventions that must be adhered to in the area of academic scholarship and research can be overpowering for doctoral candidates (Wu, \& Beaunae, 2014).

Completing a dissertation, nevertheless, is a requirement for a doctoral degree (Blum, 2010; Kuo, 2009). Candidates are required to formulate, devise, and execute an independent research study representing methodological comprehension of their field which is also expected to add to the body of knowledge. The candidates are asked to engage in independent research under the supervision of a dissertation chair and committee of professors (Alves, Azevedo, \& Goncalves, 2012; Blum, 2010). At the point when doctoral candidates embark on writing their doctoral dissertation they have completed the coursework, the comprehensive exams, and any assigned pre-dissertation research papers. A number of doctoral candidates grapple with the doctoral dissertation even though they have satisfactorily passed the required courses, passed the comps, and fulfilled any pre-research assignments. According to Burkard (2014), the devotion, time commitment, and personal effort needed to write a doctoral dissertation is too much.

Doctoral candidates confront numerous problems along the path to completing the dissertation (Blum, 2010; Cakmak et al., 2015; Barrett \& Hussey, 2015). The typical problems include: synthesization of information, conceptualization in writing, clarification of the links between the parts and the whole, decision on an appropriate voice, and completion of the paper. Barrett and Hussey (2015) suggested that candidates stand back from the writing in order to identify clearly for themselves what the main ideas, subject matter, thoughts, positions, and additions to the body of knowledge are in individual chapters and in the dissertation as a whole.

Chairs can facilitate the writing process by assisting candidates with reenergizing thought processes, avoiding writing traps, proceeding through stages, highlighting additions to knowledge, and demonstrating "doctorateness" (Barrett \& Hussey, 2015, p. 48). Visualizations or any type of visual imagery can operate meta-cognitively to permit doctoral candidates to describe their thoughts, merge and plot various aspects of the dissertation together, and 
showcase the value of their ideas and positions.

Millar (2013) maintained that, based on information provided from the 2008 Survey of Doctorate Recipients which was compared to information provided from the Survey of Earned Doctorates, candidates who conducted interdisciplinary dissertation research are more apt to secure jobs in colleges and universities than candidates who did not conduct interdisciplinary dissertation research. This opinion was in spite of the commonly held belief that interdisciplinary researchers are underrated in higher education institutions. Nevertheless, conducting interdisciplinary dissertation research does not have a dramatic effect on the types of positions held. Moreover, interdisciplinary dissertation research drastically increased chances of postdoctoral employment. This finding however is impacted by the current academic job market. Millar further maintained that conducting interdisciplinary dissertation research is also linked with higher numbers of publications than non-interdisciplinary dissertation research.

According to Cakmak et al. (2015), candidates who feel that their doctoral dissertations are not relevant to their area of interest and ability or who have not decided on academic objectives do not experience "flow" (p. 608), defined as the process of healthy connection to the area of study which enhances cognitive abilities such as feeling in control, attending to the work, being mentally satisfied, and balancing abilities with tasks. In order to experience flow candidates need to match the work with ability. If the work is above a candidate's ability, the candidate is apt to become anxious and unable to experience flow. It is imperative that candidates establish long-term academic objectives and be able to express them to experience flow. In other words, intrinsic motivation of candidates who believe that their abilities do not align with the tasks is likely to be low and therefore they will not experience flow.

Moreover, emotive connection is essential for flow. Cakmak et al. (2015) alleged that emotive connection is delight in the dissertation, energized by the dissertation, and attentive on the dissertation. Candidates tend to experience contentment and are more resilient to the problems confronted during the dissertation process. Cakmak et al. also alleged that this contentment is due to the flow experience. Contentment does not happen unexpectedly, contentment happens when abilities are matched effectively to the work.

Doctoral candidates who experience problems with attending to their dissertations are also having problems with flow. On the other hand, candidates who get lost in time are experiencing flow. All candidates might not experience flow while others experience flow more often. Flow theory according to Cakmak et al. (2015), deals with attention to work that may enhance mental abilities by feeling in control, attending to the work, being mentally satisfied, and balancing abilities with tasks.

Writing the dissertation has been compared to running a marathon (Tweedie, Clark, Johnson, \& Kay, 2013). Both pursuits can be very lonely and are substantial undertakings, require significant training and concentration to finish, and contain the possibility of failure. By failing to complete the dissertation a candidate forfeits attainment of the doctoral degree and is 
relegated to the "ABD" (all-but-the-dissertation) club (Blum, 2010, p. 75). Consequently, in their article Marino et al. (2014) suggested that candidates should consider recruiting others for support while writing the dissertation. Marino et al. (2014) further suggested that candidates consider recruiting those who are admired and dependable. Communicating with others about doubts, areas of concern, and just talking through issues can be productive.

Courses, texts, websites, tutoring, and other similar items can also provide support. There are numerous resources in the library, department, and institution that are available to assist candidates with the writing of a dissertation. Furthermore, chairs, committees, faculty, classmates, and other researchers can provide much needed encouragement and ideas during the writing stage (Marino, Stefan, \& Blackford, 2014). Tweedie et al. (2013) recommended communities of practice for support during the solitude of writing a dissertation. Tweedie et al. alleged that communities of practice assist candidates with completing the doctoral dissertation particularly in online institutions. According to Hung-Wen, (2011) the more socialization one has in an institution the more one finds satisfaction.

\section{Method of Procedure}

This research study was an archival quantitative, data mining study using data from the Integrated Postsecondary Education Data System (IPEDS) of the National Center for Education Statistics (NCES). This study identified the number of doctoral degrees awarded during the 2012-2013 academic year at public 4-year or above universities, private 4-year or above universities, and for-profit 4-year or above universities in the United States.

Data for this study were extracted from IPEDS, a system of interrelated surveys compiled each year by the NCES. IPEDS gathers information from colleges, universities, and technical and vocational institutions that are involved in federal student financial aid programs. The Higher Education Act of 1965, as amended, requires institutions that are involved in federal student aid programs to submit data on enrollment, program completion, graduation rates, faculty and staff, finances, institutional prices, and student financial aid (The Higher Education Act of 1965). These data are made available to the public through the IPEDS Data Center.

Data were extracted according to institution type in 4-year or above universities in the United States. The data were downloaded from IPEDS and converted into an Excel document. The Excel document was formatted and cleaned up.

\section{Findings}

The findings revealed the following information shown in Table1 about doctoral degrees awarded from public, private, and for-profit 4-year or above 
universities in the United States during the 2012-2013 academic year.

Table 1. 2012-2013 Doctoral Degrees Awarded According to Institutional Type

\begin{tabular}{|l|c|c|c|c|c|c|c|c|}
\hline $\begin{array}{l}\text { Institutional } \\
\text { Type }\end{array}$ & $\begin{array}{c}\mathbf{2 0 1 2 -} \\
\mathbf{2 0 1 3} \\
\text { Doctoral } \\
\text { Degrees } \\
\text { Awarded }\end{array}$ & Minimum & Maximum & Mean & $\begin{array}{c}\mathbf{2 5}^{\text {th }} \\
\text { Percentile }\end{array}$ & Median & $\begin{array}{c}\mathbf{7 5}^{\text {th }} \\
\text { Percentile }\end{array}$ & $\begin{array}{c}\text { Standard } \\
\text { Deviation }\end{array}$ \\
\hline $\begin{array}{l}\text { Public } \\
\begin{array}{l}\text { Universities } \\
\text { (N=325) }\end{array}\end{array}$ & $\begin{array}{c}87,128 \\
(50 \%)\end{array}$ & 1 & 1,964 & 268 & 28 & 116 & 361 & 351.07 \\
\hline $\begin{array}{l}\text { Private } \\
\begin{array}{l}\text { Universities } \\
\text { (N=550) }\end{array}\end{array}$ & $\begin{array}{c}81,608 \\
(46 \%)\end{array}$ & 1 & 1,727 & 148 & 9 & 41 & 185 & 247.43 \\
\hline $\begin{array}{l}\text { For-profit } \\
\text { Universities } \\
\text { (N=58) }\end{array}$ & $\begin{array}{l}7,129 \\
(4 \%)\end{array}$ & 2 & 889 & 122 & 19 & 53 & 145 & 183.04 \\
\hline $\begin{array}{l}\text { Total } \\
\text { (N=933) }\end{array}$ & $\begin{array}{l}175,865 \\
(100 \%)\end{array}$ & & & & & & & \\
\hline
\end{tabular}

Findings indicated (Table 1) that of a total of 175,865 doctoral degrees were awarded during the 2012-2013 academic year in the United States. Of the 175,865 doctoral degrees awarded, $50 \%$ (87,128) were from public universities, $46 \%(81,608)$ were from private universities, and $4 \%(7,129)$ were from for-profit universities. Specifics about the variables in Table 1 included the following:

- Student completers according to award level as were listed in IPEDS as "Doctoral Degrees."

- Universities included 4-year or above institutions in the United States according to the three institutional types.

- The institutional types were public 4-year or above, private not forprivate 4-year or above, and private for-profit 4-year or above.

\section{Discussion and Conclusions}

A preliminary review of the literature revealed that there is a problem in the United States with the completion rates of doctoral degrees. Low completion rates result in low numbers of doctoral graduates in fields requiring doctorates. Without the needed pool of doctorates various disciplines are at risk of insufficient numbers of educators and researchers to maintain those fields.

The review of the literature is replete with examples of the how important socialization is to the writing of doctoral dissertations. Chairs, committees, classmates, faculty, researchers, and others provide numerous opportunities for support to candidates during the dissertation process. Without this support, candidates are at risk for non-completion of the dissertation and ultimate completion of the doctoral degree. This is a potential loss of future resources to colleges and universities of higher education and a loss of a professional 
credential to aspiring doctors which may severely stifle or limit careers.

The findings from the study indicated that a total of 175,865 doctoral degrees were awarded during the 2012-2013 academic year in the United States. Of the 175,865 doctoral degrees awarded, 50\% were from public universities, $46 \%$ were from private universities, and $4 \%$ were from for-profit universities. These findings suggested that the vast majority of doctoral graduates are from public and private universities in the United States. Findings from a review of the literature revealed that approximately 175,865 doctoral degrees were not awarded during the 2012-2013 academic year in the United States. Findings from a review of the literature also indicated that doctoral students were not graduating due to insufficient socialization during the dissertation process. This suggests that administrators must look at the socialization process of these students to determine if this is the reason why the graduation rates are so low.

\section{Implications}

The implications from this study are numerous. To begin with, there are a number of potential doctorates who get close to being awarded a doctoral degree who never receive the academic designation. Higher education must examine its doctoral programs to avoid this loss of resources. Another implication, there are a number of doctoral candidates who are never awarded their doctoral degrees. Doctoral candidates must examine their individual support systems to determine if they provide the much needed support during the writing of their dissertations. Also, there is the implication to society of what to do with the number of ABDs in the workforce.

\section{Limitation and Delimitations}

The quantitative data for this study were extracted from the 2012-2013 academic year of institutions that reported to IPEDS. An examination of previous or subsequent years may have yielded different results. Additionally, data were only gathered from institutions that reported to IPEDS. Although the IPEDS Data Center provided large sample sizes in all sectors of 4-year and above institutions in the United States, the inclusion of institutions that did not report to IPEDS may have altered the results of this study. Finally, as with all self-reported data, it is possible that data were reported to IPEDS incorrectly. If this were the case, the Findings would yield inaccurate results. IPEDS data is also highly variable as many institutions use different qualifiers for entering their data.

\section{Recommendations}


It is recommended that this study be replicated to determine if similar findings are revealed. It is also recommended that studies be conducted to resolve the role of socialization during the dissertation writing process. Studies could be conducted to identify the rankings these institutions, the Carnegie classification system, etc. as well as the completion rates of the doctorates in these same institutions. In addition, studies could be conducted to ascertain if similar problems exist in other countries regarding the completion rates of doctoral students. It is further recommended that longitudinal studies be conducted to monitor the completion rates of doctoral degrees in the United States.

\section{References}

Alves, M. G., Azevedo, N. R., \& Goncalves, T. R. (2012). Educational research and doctoral dissertations: A review within a research community. Qualitative Inquiry, 18(7), 626-637.

Barrett, T., \& Hussey, J. (2015). Overcoming problems in doctoral writing through the use of visualisations: Telling Our stories. Teaching in Higher Education, 20(1), 48-63.

Berger, R. (2015). Challenges and strategies in social work and social welfare $\mathrm{PhD}$ education: Helping candidates jump through the dissertation hoops. Journal of Teaching in Social Work, 35(1/2), 166. http://dx.doi.org/10.1080/08841233. 2014.973548.

Blum, L. D. (2010). The "All-But-the-Dissertation" student and the psychology of the doctoral dissertation. Journal of College Student Psychotherapy, 24(2), 74-85. http://dx.doi.org/10.1080/87568220903558554.

Burkard, A. Z. (2014). Dissertation experiences of doctoral graduates from professional psychology programs. Counselling Psychology Quarterly, 27(1), 1954.

Cakmak, E., Isci, S., Uslu, F., Oztekin, O., Danisman, S., \& Karadag, E. (2015). Overview of the dissertation process within the framework of flow theory: A qualitative study. Educational Sciences: Theory \& Practice, 15(3), 607-620. http://dx.doi.org/10.12738/estp.2015.3.2606.

Hung-Wen, L. (2011). Demonstrating the importance of interactional socialization in organization. Systems Research \& Behavioral Science, 28(3), 264-269. http://dx.doi.org/10.1002/sres.1066.

IPEDS Data Center. (n.d.). The integrated postsecondary education data system [Database]. Retrieved from http://nces.ed.gov/ipeds.

Jacobs, R. L. (2013). Developing a dissertation research problem: A guide for doctoral students in human resource development and adult education. New Horizons in Adult Education \& Human Resource Development, 25(3), 103-117.

Jaeger, A. J., Sandmann, L. R., \& Kim, J. (2011). Advising graduate students doing community-engaged dissertation research: The advisor-advisee relationship. Journal of Higher Education Outreach and Engagement, 15(4), 5-25.

King, S. B., \& Williams, F. K. (2014). Barriers to completing the dissertation as perceived by education leadership doctoral students. Community College Journal of Research \& Practice, 38(2/3), 275-279.

Kuo, Y. (2009, January-February). Directing and chairing EFL doctoral student' 
qualitative research dissertations in Taiwan. Paper presented at the First Philippine International English Language Conference, Manila, Philippines.

Liechty, J., Liao, M., \& Schull, C. (2009). Facilitating dissertation completion and success among doctoral students in social work. Journal of Social Work Education, 45(3), 481-497.

Marino, J., Stefan, M. I., \& Blackford, S. (2014, December). Ten simple rules for finishing your PhD. PLoS Computational Biology. 1-4. http://dx.doi.org/10.1371/ journal.pcbi.1003954.

Mhunpiew, N. (2013). A supervisor's roles for successful thesis and dissertation. A US-China Education Review, 3(2), 119-122.

Millar, M. M. (2013). Interdisciplinary research and the early career: The effect of interdisciplinary dissertation research on career placement and publication productivity of doctoral graduates in the sciences. Research Policy, 42(5), 11521164. http://dx.doi.org/10.1016/j.respol.2013.02.004

Neale-McFall, C., \& Ward, C. A. (2015). Factors contributing to counselor education doctoral students' satisfaction with their dissertation chairperson. The Professional Counselor, 1, 185.

Osipian, A. L. (2012). Economics of corruption in doctoral education: The dissertations market. Economics of Education Review, 31(1), 76-83.

Sharmini, S., Spronken-Smith, R., Golding, C., \& Harland, T. (2015). Assessing the doctoral thesis when it includes published work. Assessment \& Evaluation in Higher Education, 40(1), 89-102.

The Higher Education Act. 20 U.S. C. §1001. (1965)

Tweedie, M. G., Clark, S., Johnson, R.C., \& Kay, D. W. (2013). The "dissertation marathon" in doctoral distance education. Distance Education, 34(3), 379-390. http://dx.doi.org/10.1080/01587919.2013.835778

U.S. Department of Education, National Center for Education Statistics, 1988-89 through 2009-10 Integrated Postsecondary Education Data System, "Fall Enrollment Survey" (IPEDS-EF:88-99); "Completions Survey" (IPEDS-C:8999); "Institutional Characteristics Survey" (IPEDS-IC:88-99); Fall 2000 through Fall 2009; and Spring 2001 through Spring 2010. (This table was prepared October 2010.)

Wisker, G., \& Robinson, G. (2014). Examiner practices and culturally inflected doctoral theses. Discourse: Studies in the Cultural Politics of Education, 35(2), 190-205. http://dx.doi.org/10.1080/01596306.2012.745730.

Wu, C. V., \& Beaunae, C. (2014). Personal reflections on cautions and considerations for navigating the path of grounded theory doctoral theses and dissertations: a long walk through a dark forest. International Journal of Social Research Methodology, 17(3), 249-265. http://dx.doi.org/10.1080/13645579.2012.729392. 
